The Texas Medical Center Library

DigitalCommons@TMC

UT School of Public Health Dissertations (Open

Access)

School of Public Health

Summer 8-2019

\title{
“HE'S NOT TOO YOUNG": EMPOWERING PARENTS IN CHILD LANGUAGE DEVELOPMENT THROUGH UPWORDS, A PARENTING EDUCATION PROGRAM
}

LYNDA CHIMA ARIRIGUZO

UTHealth School of Public Health

Follow this and additional works at: https://digitalcommons.library.tmc.edu/uthsph_dissertsopen

Part of the Community Psychology Commons, Health Psychology Commons, and the Public Health Commons

Recommended Citation

ARIRIGUZO, LYNDA CHIMA, "'HE'S NOT TOO YOUNG": EMPOWERING PARENTS IN CHILD LANGUAGE DEVELOPMENT THROUGH UPWORDS, A PARENTING EDUCATION PROGRAM" (2019). UT School of Public Health Dissertations (Open Access). 90.

https://digitalcommons.library.tmc.edu/uthsph_dissertsopen/90

This is brought to you for free and open access by the School of Public Health at DigitalCommons@TMC. It has been accepted for inclusion in UT School of Public Health Dissertations (Open Access) by an authorized administrator of DigitalCommons@TMC. For more information, please contact digitalcommons@library.tmc.edu.

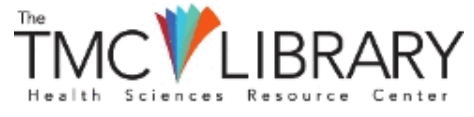


"HE'S NOT TOO YOUNG": EMPOWERING PARENTS IN CHILD

LANGUAGE DEVELOPMENT THROUGH UPWORDS,

A PARENTING EDUCATION PROGRAM

by

LYNDA CHIMA ARIRIGUZO, BS, MD

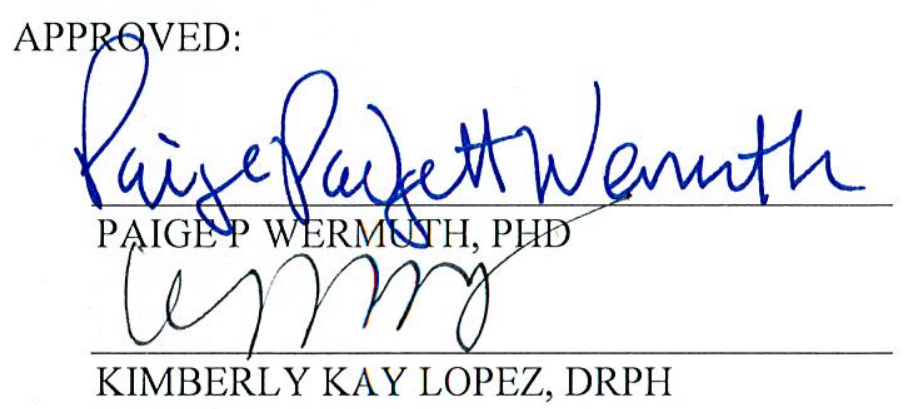




\title{
“HE'S NOT TOO YOUNG”: EMPOWERING PARENTS IN CHILD LANGUAGE DEVELOPMENT THROUGH UPWORDS, A PARENTING EDUCATION PROGRAM
}

\author{
by
}

LYNDA CHIMA ARIRIGUZO, BS, MD

APPROVED:

PAIGE P WERMUTH, PHD

KIMBERLY KAY LOPEZ, DRPH 


\section{Copyright}

by

Lynda Chima Aririguzo, BS, MD, MPH

2019 


\title{
“HE'S NOT TOO YOUNG”: EMPOWERING PARENTS IN CHILD \\ LANGUAGE DEVELOPMENT THROUGH UPWORDS,
}

A PARENTING EDUCATION PROGRAM

\author{
by \\ LYNDA CHIMA ARIRIGUZO \\ BACHELOR OF SCIENCE, Tulane University, 2008 \\ DOCTOR OF MEDICINE, The University of Texas Health Science Center at Houston \\ Medical School, 2013
}

\author{
Presented to the Faculty of The University of Texas \\ School of Public Health \\ in Partial Fulfillment \\ of the Requirements \\ for the Degree of
}

MASTER OF PUBLIC HEALTH

THE UNIVERSITY OF TEXAS

SCHOOL OF PUBLIC HEALTH

Houston, Texas

August, 2019 


\section{ACKNOWLEDGEMENTS}

I would like to thank Drs. Cary Cain and Kimberly Lopez for the time and expertise that they contributed to this research project. 


\section{“HE'S NOT TOO YOUNG”: EMPOWERING PARENTS IN CHILD LANGUAGE DEVELOPMENT THROUGH UPWORDS, A PARENTING EDUCATION PROGRAM \\ Lynda Chima Aririguzo, BS, MD, MPH \\ The University of Texas \\ School of Public Health, 2019}

Thesis: Lynda Chima Aririguzo, BS, MD

Community-based early literacy intervention programs show promise in improving the home language environment, particularly for children at increased risk of language delays and poor school readiness. However, the literature on parents' perspective of these programs is limited. This study investigated the perspectives and language scores of participants in upWORDS, a community-based literacy intervention program in Houston, TX. Through

mixed-methods, this study aimed to describe the program's impact on parents' views on child development, changes in child behaviors, and continued application of information from the program. It also aimed to identify patterns in parent-reported measurements of children's language skills over time. The primary investigator (PI) conducted secondary analysis on semi-structured interviews of parents who had completed upWORDS at least 1 year before the interview. Secondary quantitative data analysis was also done on LENA Snapshots, the parent-reported measurements of children's language skills. Qualitative analysis revealed 2 themes. The theme of child development included 3 subthemes: child's interest in reading, child's communication, and concerns about child development. The theme of parent knowledge and behavior change included 5 subthemes: awareness of developmental delay, 
better understanding of normal child development, impact on childcare and school, parentchild interaction, and challenges to applying program information and sustaining behaviors. Snapshot results tended to improve by the end of the program but improvements were not sustained. There was no correlation between Snapshot results and parents' report of challenges or sustained behavior changes. Overall parents reported multiple sustained benefits of the program that can be helpful for early literacy program implementers and pediatric primary care providers. Future steps should include a larger study to better characterize Snapshot patterns. 


\section{TABLE OF CONTENTS}

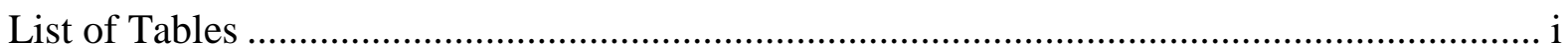

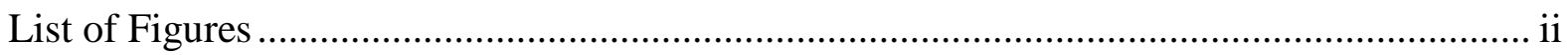

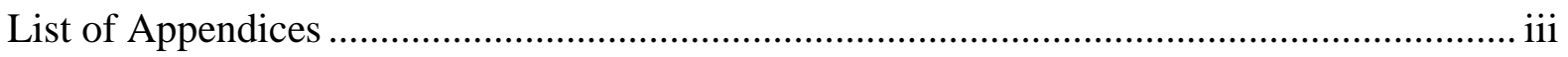

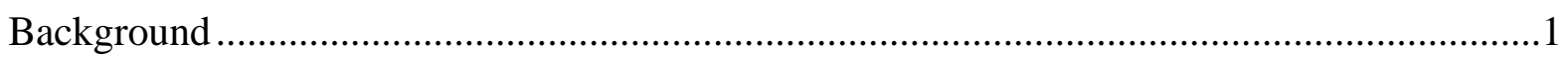

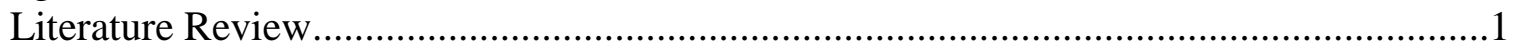

Public Health Significance ....................................................................................6

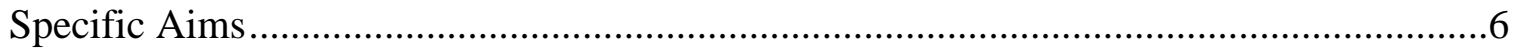

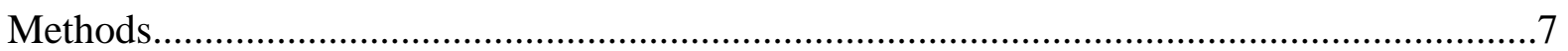

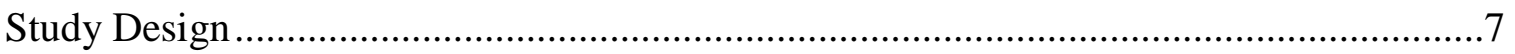

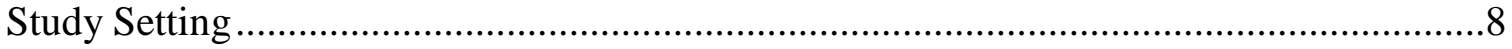

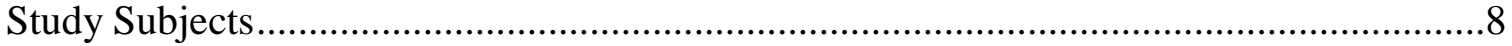

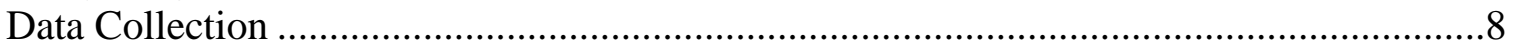

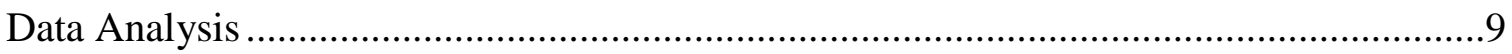

Human Subjects and Safety Considerations ................................................................10

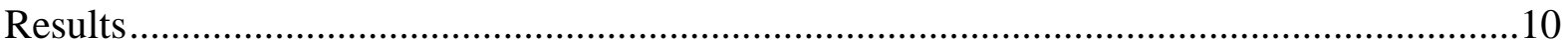

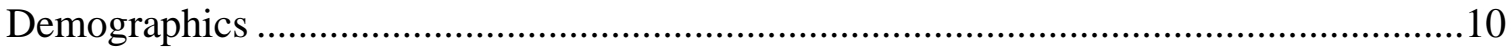

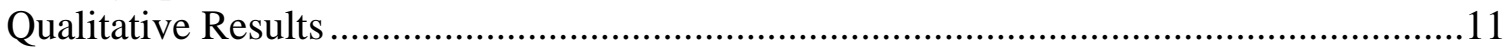

Theme 1: Child Development ...............................................................................11

Theme 2: Parent Knowledge and Behavior Change ……………...............................14

Quantitative Results ..................................................................................................20

Integrating Quantitative and Qualitative Results ..............................................................20

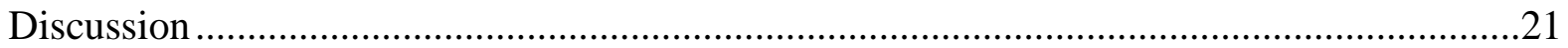

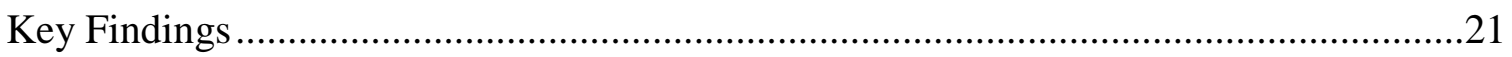

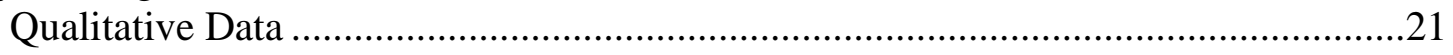

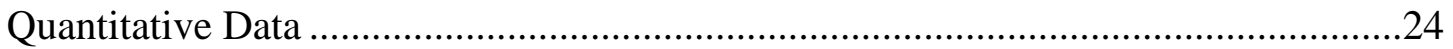

Integrating Quantitative and Qualitative Data ........................................................25

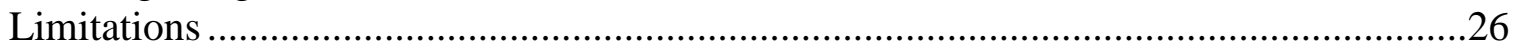

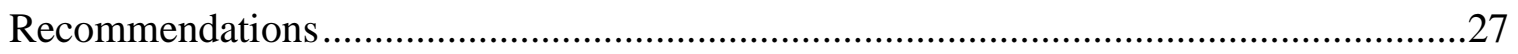

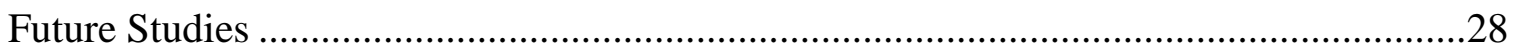

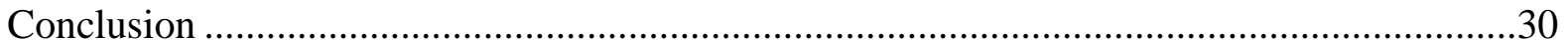

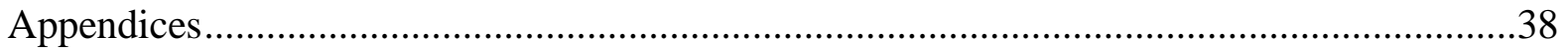

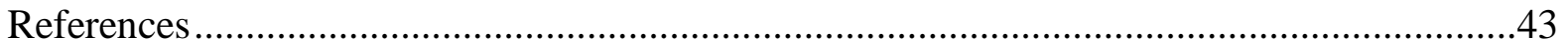




\section{LIST OF TABLES}

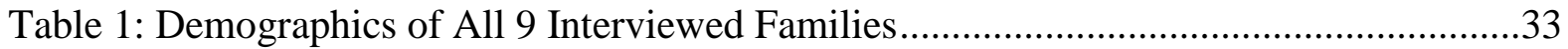

Table 2: Child Demographics from Online Survey, based on 5 total respondents ..................33

Table 3: Parent Demographics from Online Survey, based on 5 total respondents ................34

Table 4: Snapshot Standard Scores (SS) submitted by interviewed parents ........................36 


\section{LIST OF FIGURES}

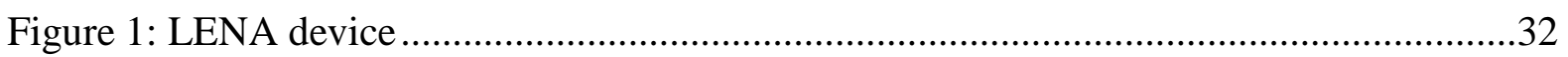

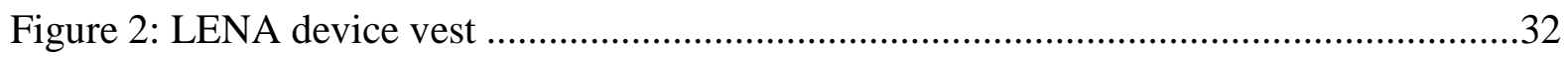

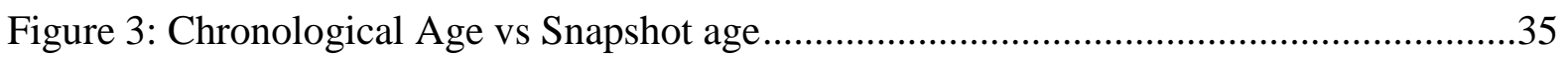

Figure 4: Snapshot Number vs. Snapshot Standard Score ..................................................37 


\section{LIST OF APPENDICES}

Appendix A: LENA Start Curriculum Outline ..................................................................38

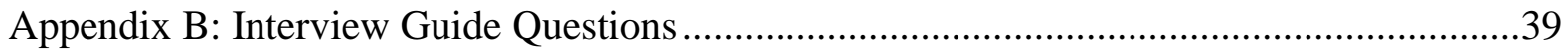

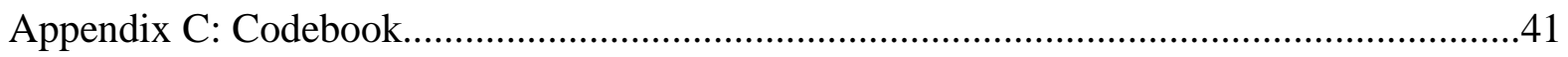

Appendix D: Baylor College of Medicine IRB Letter of Approval ...................................42 


\section{BACKGROUND}

\section{Literature Review}

Academic achievement carries a major role in one's overall health. Increased educational attainment, for example, allows for multiple positive cumulative effects across a life course (Cohen \& Smye, 2013; Hahn \& Truman, 2015). These positive effects include, but are not limited to, an enhanced sense of personal control and knowledge to allow healthier life choices, higher health literacy, and increased income, which allows increased access to healthy foods, safe environment, and health care (Hahn \& Truman, 2015). Unfortunately, a gap in academic achievement between children of high socioeconomic status (SES) households and low SES households has been well documented in the literature (Hair, Hanson, Wolfe, \& Pollak, 2015; Duncan, Morris, \& Rodrigues, 2011; Hart \& Risley, 2003). Furthermore, young children in low SES households are at higher risk of cognitive and expressive speech delays (Hillemeier, Farkas, Morgan, Martin, Maczuga, 2009; Hammer et al., 2017), and access developmental services less frequently (Porterfield \& McBride, 2007). Forty-one percent of children in the United States live in low-income families, or families with an income less than $200 \%$ of the federal poverty level; among children younger than age 9 years, this percentage increases to $44 \%$ (Koball, \& Jiang, 2018). While a substantial number of children across the United States are at risk of experiencing the academic gap, rates are even higher in Texas. In Texas, $48 \%$ of children live in low-income families and $51 \%$ of children under age 6 years live in low income families (National Center for Children in Poverty, 2018). 
Multiple factors contribute to the academic achievement gap; one major factor is the early language environment. Studies have shown that a child's language environment will vary in association with SES. Hart and Risely (2003) found that by age 3 years of age, a child from a low SES household will have heard 30 million fewer words than his/her higher SES counterpart, and that up to $96 \%$ of a child's vocabulary by age 3 consists of words found in their parents' vocabularies. More recent studies have disputed that the "30 million word gap" between a child of low SES households and his/her higher SES counterparts may be less than 30 million (D. Sperry, L. Sperry, \& Miller, 2018). However, it is undisputed that a gap in children's language does exist between socioeconomic standing and that quality of speech exposure plays a factor (Golinkoff, Hoff, Rowe, Tamis-LeMonda, Hirsh-Pasek, 2018). The "30 million word gap," coined by Hart and Risely, has become a catchy phrase that has alerted the public's attention to the relationship between SES and early language exposure. Low SES is furthermore associated with low child vocabulary at 48 months of age and lower school readiness at time of school entry at 60 months of age (Hammer et al., 2017). Poverty can even be linked to structural differences in the brain that are associated school readiness skills (Hair, Hanson, Wolfe, \& Pollak, 2015). This disparity often persists beyond school entry. Language skills, including oral language skills acquired in early childhood, are associated with better language skills and reading comprehension in third grade (Hart \& Risley, 2003; NICHD Early Child Care Research Network, 2005).

In an attempt to increase school readiness and decrease the academic achievement gap, parents can be encouraged to enhance the home language environment, particularly before school entry. For example, parents can be directed to increase the amount of speech 
directed to their children, or child-directed speech. Toddlers who hear more child-directed speech have been found to have larger vocabularies and to be more efficient in language processing (Weisleder \& Fernald, 2013). Similarly, increased maternal responsiveness, such as playing, imitating, or describing things to her child, has been found to be a strong predictor of timing of language milestone acquisition (Tamis-LeMonda, Bornstein, \& Baumwell, 2001). The American Academy of Pediatrics recommends that pediatric providers encourage parents to adopt behaviors that promote children's social, emotional, and language development, in an effort to reduce childhood experiences linked to costly health disparities in adulthood (Garner et al., 2012). Clinic-based literacy interventions, such as Reach out and Read, have been effective at increasing parent-child reading activities, improving the home literacy environment, and increasing children's scores in expressive language, receptive language, and literacy (Mendelsohn et al., 2001; Diner, Hobson-Rohrer, \& Byington, 2012). While successful, clinic-based literacy interventions may not reach children who do not have a primary care medical home or who attend clinics where the interventions are not provided. This is especially true for children from low SES households, who may have less access to regular primary care and may access development services less frequently but who are at higher risk of language delay, poor school readiness, and lower academic achievement. Literacy intervention programs outside of the clinical setting also show promise in improving parent knowledge and verbal interaction between parent and child in the form of conversational turns (Suskind et al., 2015). However, these community-based literacy intervention programs can vary in curriculum and approach. The literature on parents' perspective of such programs is limited. Parents' perspective on these community-based, 
parent-targeted interventions would be invaluable. Their views could be used to evaluate these programs and to provide insight on the fidelity of the intervention. Furthermore, the parents' perspective could allow for understanding how behaviors taught in these interventions can be better adopted by future participants.

One such community-based literacy intervention program is the upWORDS program at Baylor College of Medicine/Texas Children's Hospital in Houston, TX. UpWORDS is designed to be a 14-week program for parents and children age 0 to 24 months. It utilizes the Language Environment Analysis (LENA) Foundation LENA Start curriculum, a standardized parent education program, and enhances the curriculum with parenting support topics. Parents/caregivers meet with trained staff for 1 hour-per-week sessions in which they learn how to enhance the early language environment through practical skills of interacting with their child. LENA Start curriculum contains 13 sessions; concepts taught during these sessions include rapid brain development during the first 3 years of life, the impact of childdirected speech, conversational turns, and regular reading have on the developing brain, making story time a routine, using songs and play, and learning how to engage their children in various settings. Throughout the sessions, parents learn and review LENA's 14 Talking Tips, a list of practical ways to increase child-directed speech and conversational turns with their children. A weekly outline of the LENA Start curriculum is provided in Appendix A. In addition to the LENA Start curriculum, upWORDS covers various parenting support topics, including managing stress, postpartum depression, safe sleep environments, car seat safety, and positive parenting strategies. Parents complete LENA recordings one day a week using LENA devices. A LENA device is a small, lightweight recorder that, when connected to 
LENA software, automatically aggregates the child vocalization count, the adult word count spoken to the child, and the number of conversational turns between child and adult. It also aggregates the amount of time the child is exposed to electronic sounds, such as television. The LENA device is placed in the pocket of a vest that the child wears on recording days. Recordings last 16 hours. Figures 1 and 2 show the LENA device and vest worn on recording days. Through LENA technology design, no one is able to hear these audio recordings; specific words spoken cannot be assessed. At the end of most weekly sessions, the parents receive an individualized graphical report of the data collected from their LENA devices. This allows parents to track their progress and to see how their families' language environment compares to others. Every week after week 4, parents also submit via text message an estimate of the number of minutes per day that they read to their children. These reading minutes are included on their reports, along with the daily minimum reading minutes goal taught in the LENA Start curriculum. If a parents meets or exceeds goals for word counts, conversational turns, and reading minutes, he or she is rewarded by receiving stars on the weekly report. Furthermore, parents/caregivers also complete LENA Developmental Snapshots before, during, and after the program. The Snapshot is a validated 52-item parent questionnaire that assesses expressive and receptive language skills and can give an estimate of language development even in the absence of a trained professional. It was designed to not only to be a monthly progress monitoring tool but also to allow parents to more easily identify language milestones (Gilkerson, Richards, Greenwood, Montgomery, 2016). The Snapshot is available in English and Spanish. The raw scores of the Snapshot are converted age-standardized scores, or standard scores (SS) along a normal distribution (Gilkerson, 
Richards, Greenwood, Montgomery, 2016). The mean SS is 100, with a standard deviation (SD) of 15. Minimum SS is $64\left(-2.4 \mathrm{SD}\right.$, or $<1^{\text {st }}$ percentile $)$ and maximum SS is $136(+2.4$ SD or $>99^{\text {th }}$ percentile). Snapshots also are used to estimate a developmental age, with the developmental age expected to be equivalent to actual chronological age in a normally developing child.

\section{Public Health Significance}

The literature on parents' perspective of such community-based literacy programs is limited. Parents' views could inform design and implementation of these programs, allowing for improvement and potential expansion in order to best serve at-risk children and their families. Such research in community-based literacy programs could help improve children's language development and academic achievement, which could help decrease some adult health disparities.

\section{Specific Aims}

This study analyzed the perspective of parents who are at least 1 year beyond graduation from the Baylor College of Medicine/Texas Children's Hospital upWORDS program. It qualitatively seeks to describe any changes in parents' thoughts on child development attributed to upWORDS participation, to evaluate the continued application of LENA Start principles after completion of the program, and to characterize the programs' impact on their children's language development. In addition, this study seeks to identify patterns in language skills among participating children through quantitative analysis of a small cohort of parent-reported Snapshots. This quantitative analysis may add depth to the information gained from the parents' perspective. 
This mixed methods study of the upWORDS program will reveal helpful aspects of the program. The information obtained from this study will potentially also inform other early language intervention programs both within and outside of the clinical setting.

\section{METHODS}

\section{Study Design}

This study is a secondary data analysis of interviews conducted by the Baylor College of Medicine/Texas Children's Hospital upWORDS research team. Past participants of the upWORDS program who completed the program at least 6 months prior to interviews were recruited. Participants for this study were recruited by invitation via email (REDCap system), text message (LENA Mobile Online system), or phone call. When a response was received, a follow-up email, text, or phone call was done in order to schedule a phone interview. By participating in the phone call, the participant consented to be a part of this study.

Phone interviews of participants were conducted by the research team. Each interview lasted approximately 30 minutes. The research team developed a semi-structured interview guide (Appendix B) for the individual interviews. Topics in the guide included parents' reflections on their interaction with their children in light of the upWORDS program, perception of their own knowledge and behavior change, strengths and weaknesses of the program, and perceptions about their children's development. For secondary data analysis, upWORDS provided phone interview notes, audio files, and transcripts. UpWORDS also provided data on their participants, including demographics, reports from weekly recordings, and Snapshot results. 


\section{Study Setting}

This study primarily focuses on post-program interviews conducted over the phone as well as LENA Developmental Snapshots for participants who previously attended upWORDS sessions in the Houston, TX area.

\section{Study Subjects}

Participants were adult parents and/or caregivers, age 18 years or older, whose children were age 0-24 months at the start of their upWORDS program. The term "parent" in this study refers to participants as defined above. In addition, participants of this study completed the LENA Developmental Snapshots at the start of their program, at the end of their program, and at least 6 months after completing their program. Because upWORDS sessions were conducted in English and Spanish, participants of this follow up study spoke English and/or Spanish. Interviews were conducted in the participant's language of choice, either English or Spanish. At the time of primary data collection, 67 children had completed the upWORDS program; all of their parents were invited to be interviewed. Sixteen parents consented to be interviewed. Of these parents, 11 of them had submitted 5-6 LENA Developmental Snapshots. The sample size of this study was 9 participants, which was a convenience sample of the 11 parents.

\section{Data Collection}

Interview notes, transcripts, audio files, Snapshot scores, and participant information collected by investigators with Baylor College of Medicine/Texas Children's Hospital upWORDS program were used for secondary analysis. 


\section{Data Analysis}

For qualitative analysis of the interview data, thematic analysis was used. Phone interview data included audio recordings, transcriptions, and interview notes. Thematic analysis involves reading and rereading the interview data in order to identify patterns and categories across the data (Glaser \& Strauss, 1967). A codebook was created from the initial reading of interview data to create a guide for analysis. Data from interviews were aggregated to determine themes of parents' experiences and views. Themes were identified based on the subject content of the interviews and the repetition of key words. This process involved using a series of iterative comparisons between data sources (interview notes and transcripts) to determine similarities. For trustworthiness of qualitative analysis, the data was coded independently by the primary reviewer. The primary reviewer routinely discussed all codes with 2 other reviewers to establish consensus.

The primary investigator (PI) analyzed Snapshot data for the 9 interview participants. Snapshot data included sequence of Snapshot, estimated developmental age, and standard score (SS). Each participant completed 1 Snapshot at baseline, 2 Snapshots during the program, 1 Snapshot on the last day of class, and 1-2 Snapshots upon program completion. The PI analyzed 5 to 6 Snapshots per participant, for a total of 52 Snapshots. The PI also reviewed demographic data. 


\section{Human Subjects and Safety Considerations}

Approval for this study was obtained by the Baylor College of Medicine Institutional Review Board (Baylor protocol number H-40882) and the University of Texas Health Science Center at Houston Institutional Review Board, Committee for Protection of Human Subjects (University of Texas protocol number HSC-SPH-19-0129). A copy of the Baylor protocol approval letter is available in Appendix D. Participants of this study gave oral consent to participate. Transcripts, interview notes, audio files, and participant information were stored electronically on Texas Children's Hospital encrypted computers. This data was password-protected and accessed electronically through the secured Baylor College of Medicine/Texas Children's Hospital network.

\section{RESULTS}

\section{Demographics}

Table 1 shows the demographic information of the 9 participants. Characteristics included child's gender, language of session instruction, total snapshots completed, mean and median age of child, and time elapsed between last class day and post-program snapshots. Tables 2 and 3 show demographics obtained from 5 of the 9 participants during the online survey. Table 2 pertains to participating children and includes information on ethnicity, race, health insurance coverage, history of neonatal intensive care unit (NICU) admission after delivery, newborn hearing screen status, and whether a medical professional had diagnosed them with special needs. Special needs included developmental delay, learning disability, speech delay, or emotional disorder. Table 3 pertains to the parents and details relationship 
status to child, ethnicity, race, marital status, age, country of birth, education level, public assistance status, and annual household income. Public assistance was defined as receiving help to pay for food, bills, housing, medical costs, or medical insurance (such as housing subsidy, WIC, Food Stamps, SNAP, or Medicaid).

\section{Qualitative Results}

Qualitative analysis of the interviews revealed 2 large themes: child development and parent knowledge and behavior change. A schematic of the codebook is included in Appendix C. The child development theme encompassed 3 subthemes: child's interest in reading, child's communication, and concerns about child's development. The theme of parent knowledge and behavior change included the following 5 subthemes: awareness of undiagnosed developmental delays, better understanding of normal child development, impact on decisions concerning childcare and school, parent-child interaction, and challenges to incorporating and sustaining behaviors from the program. The number of parents who endorsed a statement or subtheme is included in parentheses. Names within quotes were changed to protect the identities of the families involved.

\section{Theme 1: Child Development}

The first theme, child development, include 3 subthemes that describe the parents' perspectives of their children's development. These subthemes are child's interest in reading, child's communication, and concerns about child's development.

\section{Subtheme 1: Child's Interest in Reading}

Some parents (3) noted their children had established had an interest in reading after upWORDS. Parents reported that their children liked to select books, bring books to parents, 
and read with parents or pretend to read to their parents. One parent explained that her daughter seeks out books for fun, stating that "She loves to read or she looks for books when she is playing and she likes when we read to her." After session 4 of upWORDS, families who achieved their minimum reading minutes goal received a star on their weekly reports. This served as another way to encourage reading in the home. Families participating in upWORDS also received a free children's book at the end of each session. As a result, families had increased exposure to age-appropriate books in their homes. One parent described the benefit of having the books from upWORDS, stating, "I have a table in the living room with all the stories from the program and he is always grabbing them and even takes them to the car."

\section{Subtheme 2: Child's Communication}

Parents also perceived positive changes in their children's communication after the program. Almost half of parents (4) gave examples regarding perceived improvements in their children's expressive language. Almost half of parents (4) noted how much more their children talked after upWORDS. One parent stated "Well I think he began to talk a bit more when I went to LENA [upWORDS]. He didn't talk very much, and I think he has improved a lot because he has been using LENA and has advanced a lot.” A few parents (2) noted that their children were able to express themselves very well; communicating with their children seemed easier than communication between their peers and their peers' children. One parent explained "When I was pregnant my coworker gave me this book about how to communicate with babies and toddlers, but I never had to use it with [my daughter] because she uses words and is able to make her point." Another parent recognized that their child's increase in 
expressive language was a result of increased child-directed speech, stating "She is using more words because we talk more to her".

While parents largely described perceived improvements in expressive language, some (3) also perceived improvements in their children's receptive language. Some parents were surprised by the extent of their children's understanding. One parent accounted, "A few months back my mom had her in a video chat and they were talking about horses and [daughter] goes, 'No that's not a horse, that's a zebra.' And my mom was surprised she knew the difference and we now know she's a sponge and understands big words."

\section{Subtheme 3: Concerns about Development}

Parents were asked if they and/or their children's doctor were concerned about their children's development. The majority of parents (7) had no concerns. Many were able to compare their children with other children to explain why they weren't concerned. Similarly, most parents (7) stated that their doctors were not concerned about their children's development. Four parents, however, reported concerns even though their doctors were not concerned. One parent explained "The pediatrician says he is fine, but I feel like he should be talking more. I do compare him with other family members." Still, 3 out of these 4 parents had initially stated that they had no concerns and later shared that they had concerns. One parent explained,

[My daughter] is not putting 2 words together. She is saying "abuela," "mama," "luz," "Moises," which she says perfectly but sometimes she says it incorrectly. "Water." The only time she puts 2 words together she said "Moises y yo pollo" and everything she eats is "pollo." 
Additionally, 3 parents consistently stated that they had concerns about their children's development, including the 1 parent whose doctor was not concerned. Some children (2) had speech delays that were first noticed while attending upWORDS. UpWORDS is a unique LENA Start program in that speech language pathologists have leading roles. Participating children, particularly those with undiagnosed speech delay, were regularly exposed to speech language pathologists who can easily recognize language issues. Explaining her current concerns and the guidance received from upWORDS leaders, one parent said the following:

I think he is behind in his speech. He has been to speech therapy when he went to LENA. [The facilitator] told me he was behind and to look for speech therapy, which is why I put him in it, and now he speaks a bit more, but I think he should be talking more. He only repeats things and doesn't really talk.

\section{Theme 2: Parent Knowledge and Behavior Change}

Subthemes within the theme of parent knowledge and behavior change included awareness of developmental delay, better understanding of normal child development, impact on childcare and school, parent-child interaction, and challenges to applying information and sustaining behaviors.

Subtheme 4: Awareness of Developmental Delay

As stated earlier, upWORDS allowed some parents (2) to become aware of undiagnosed developmental delays, specifically speech delays, in their children. One parent said, "To an extent, the program helped me sense a problem with his language." Without knowledge acquired through upWORDS, some parents may have never recognized developmental delay in their children or may have recognized it much later. 


\section{Subtheme 5: Better Understanding of Normal Child Development}

Because of the program, most parents (6) gained a better understanding of normal child development. One parent remarked, "My expectations for my son's development were higher because of the program." Parents also learned what activities foster normal, healthy development. Another parent explained, "One of the teachers said at that age they know what they want or need, so she gave an example of how we can try to help with options, and I've done that with [my daughter] since then." Some parents (3) described how the program specifically increased their knowledge of normal language development. One parent explained, "My daughter is premie by about 2 months. Her doctor has a lot of good information about physical development but not as much on vocabulary. UpWORDS tends to focus on that." In addition, several parents (4) discussed how the program empowered them to be key agents in their children's development. For example, one parent said that she benefited from

Learning something that culturally I didn't have or know or didn't know I was capable of doing because I wasn't raised that way. I wasn't raised in a home where you got to read or spend quality time, or describing and being descriptive about what we're doing.

The program had an additional influence on knowledge of normal child development: encouraging early engagement. Some parents (3) realized that they should engage their children at an earlier age in activities typically associated with learning because they are not too young to learn. One parent mentioned the following: 
Before that, I thought they were babies and they didn't understand anything, but they do, like right now I'm trying to teach her numbers and she recognizes the numbers, but before the program, if I hadn't done it then I would have thought "oh she doesn't know this. They're not going to learn it until they're 4 or 5 .

Another parent, explaining the newly-learned benefit of engaging her infant early, said the following:

With my first child, I would say "Well he's too young. He doesn't know." Or he wouldn't pay attention when I would read to him. And they taught me that it doesn't matter if he isn't paying attention to the book, but the child is listening, always listening, and that's how they learn, and I think people tend to ignore that.

\section{Subtheme 6: Impact on Childcare and School}

Parents were asked if upWORDS had an impact on their decisions concerning child care, daycare, babysitting, and/or school. The majority of parents (7) reported that the program had impacted their decisions. They changed their views and selection of child care, daycare, babysitting, and/or school in order to incorporate principles of child development learned from the program. One parent explained the following:

I didn't realize daycares should be having activities with kids and to dedicate time to the kids. [...] Now I have more knowledge in development, and I would ask them if I were to take them to daycare "other than just taking care of my kids, what else can you do with my child?" 
Another parent, describing her selection process of babysitters, said "Even with my own parents, I'm very selective because sometimes I know that won't take place, that interaction.” Few parents (2) reported that the program had no impact on how they chose child care, daycare, babysitting, or school. This, however, was because they did not use daycare. One parent responded, "No I haven't thought about any of this. My kids are not in a daycare because I can't afford it.”

\section{Subtheme 7: Parent-Child Interaction}

In addition, most parents (6) reported that they learned more about parent-child interaction. They learned practical ways to increase parent-child interaction overall and to make it routine. When pointing out the most impactful parts of the program, a parent said, "I would say the importance of engaging with your child [. . .] reading, sitting down with them, paying attention to what they are doing. I would say that was the biggest thing." Another parent added that the program "taught us more communication during other times such as before bed time, more during play time, more reading, which is now a habit." Parents were introduced to a variety of techniques to interact with their children, which some new parents found especially helpful. One parent explained "He's my first and only child. It gave me more options on how to interact with him."

Furthermore, parents shared specific techniques related to parent-child interaction that were either learned or enhanced by upWORDS. These techniques included narrating, reading, talking, and screen time adjustments. Some (3) specifically mentioned narrating as a way to enhance the home language environment. One parent said that around her child she is "explaining and describing things. I do that a lot now that I'm more aware because I know 
that it helps his development. I got used to it." Narrating had become such a regular technique for the parents of another family that their older child routinely narrated to their younger children. The majority of parents (8) stated that the program helped them with reading to their children. Parents reported reading more with their children, as one stated, "So yeah, we read a lot. I like that for her. My love for reading was discovered late in my life and I want her to have that early in life." They also reported that upWORDS helped reading become a routine, and that they appreciated the specific reading guidelines. One parent mentioned a benefit of the program was the "age correlating to the recommended number of minutes that your child should be read to. It was helpful that it gave solid guidelines." Most parents also said that upWORDS helped them become more intentional about talking with their children. One parent stated that the program "has given me ideas on how to converse with her on a daily basis." Another parent cited "the correlation between verbal communication and a kid's learning capabilities," as motivation for talking more with her child. Some families increased parent-child interaction as a result of changed views on screen time. Three parents reported decreasing their children's screen time because of the program, exchanging TV and tablets for other activities. For one parent, the most important thing learned from the program was "to read to your child and interact with them verbally and show them how to do things, rather than letting TV or iPad or other electronic devices to teach them". Another parent explained while her family didn't completely eliminate screen time, they understand screen time should be limited. She stated the following: 
She does have, uses the iPad and what not, but we know that there is a time to do that. We try not to give it to her during the day. We try to give it to her for a little bit and then at night it's reading time and she enjoys that.

\section{Subtheme 8: Challenges to Applying Information and Sustaining Behaviors}

Parents were also asked if they experienced challenges to applying information and sustaining behaviors that they learned through upWORDS. Most parents (6) stated that they had no barriers to applying information learned. The majority (8) said that they were able to sustain behaviors that improved their interactions with their children. Some parents (3) reported that they experienced barriers to applying the information taught in the program. Barriers included lack of time, social structural changes affecting family life, and using a caregiver that did not apply the same information from upWORDS. A few parents (3) said that they were not able to sustain all their behavior changes, stating that they only continue some behaviors or that they now have less time for certain behaviors like reading and reviewing the alphabet. Only 1 parent consistently said that she was not able to sustain any changes regarding interacting with her child. One way to measure sustained change from the program was to ask about caregiver reading minutes count in the interview guide. Parents learned minimum reading minutes goals according to their children's age. The age range of the children at the time of the interviews was 21 months to 3 years. Per reading minutes guidelines, these children should receive a minimum of 20 to 30 minutes of reading per day. While the majority of parents (8) made sure that their children had reading time after the program was over, only 5 of the children involved were actually meeting the minimum goal of 20 to 30 minutes per day. Three children received 5-15 minutes of reading per day. One 
child did not receive any reading time at all. This child's parent was the same parent who consistently said she was unable to sustain behavior changes after completing the program.

\section{Quantitative Results}

Snapshot data was also analyzed. Figure 3 is a graph of the actual ages of the 9 children vs their developmental age, or Snapshot age, at each of their Snapshots. In general, developmental age was at or below chronological age at baseline, improved by the fourth Snapshot, and dropped back to baseline or below baseline after the program ended. Table 4 details the difference between the Snapshot SS and the average SS of 100 and notes the mean difference in scores for each Snapshot. The SS mean was close to the average SS at baseline, decreased at the second Snapshot, peaked at by the last class day (fourth Snapshot), and then dropped after the end of the program. Figure 4 is a graph of the Snapshot order vs the SS for each child. The dashed lines represent SS values of expected mean SS (100), -2 standard deviations (70), and +2 standard deviations (130). Overall, the second SS was lower than the baseline SS. Scores peaked at the fourth Snapshot and decreased to baseline or below baseline after the program ended (fifth and sixth Snapshots).

\section{Integrating Quantitative and Qualitative Results}

Comparing Snapshot data with data from interviews, there was no correlation between Snapshot scores and whether minimum reading minutes were met. There was no correlation between final Snapshot score and endorsement of barriers, no barriers, sustained change, and unable to sustain change. For example, one parent reported that her child had speech delay and attended speech therapy. This child's SS were approximately -2 SD at baseline, peaked close to average at the end of the program, and then returned to 
approximately -2 SD months at the final Snapshot. During the interview, this parent explained that the family had no barriers, was able to sustain some behavioral changes regarding interacting with their child, did not use daycare, and was still reading to the child but were not meeting their minimum reading minutes goal. Furthermore, another parent discussed that they were unable to sustain any behavior changes after the program and that the child received no reading time after completing upWORDS. This child's SS curve was unremarkable, with a final score slightly lower than the baseline.

\section{DISCUSSION}

\section{Key Findings}

\section{Qualitative Data}

Results from analysis of the interviews revealed several important findings. First, parents gained a better understanding of normal child development through upWORDS. This allows parents to better understand their children's behavior, to better anticipate their needs, to create appropriate rules and routines, and to engage their children in developmentally appropriate activities. This supports evidence that parents who underestimate their children's abilities have poorer quality interactions during certain tasks (Huang, Caughy, Genevro, \& Miller, 2005). As they learned about normal development, some parents became aware of their children's developmental delays and were able to pursue appropriate intervention earlier. They avoided delayed diagnosis and treatment of language delays. Given that language delays by age 24 months can be associated with low vocabulary at 48 months and 
low level of school readiness at 60 months (Hammer et al., 2017), early intervention against language delay may help improve school readiness later. Recognizing language delay early is also important because language delay can be associated with other disorders, such as hearing impairment, autism spectrum disorder, cognitive impairment, and other developmental disorders (McQuiston \& Kloczko, 2011). Understanding normal child development may play a role in child abuse prevention, as parent risk factors for child abuse include decreased of awareness of child development and unrealistic expectations that hinder the parent from grasping the child's needs and behaviors (Butchart, Harvey, Mian, \& Fürniss 2006).

Another important finding was that despite unstained improvements in Snapshot developmental age and SS (see discussion section on quantitative data), parents still perceived multiple benefits from upWORDS. Parents liked that they learned how to interact more with their children. They even named specific learned techniques that help them sustain increased interaction with their children: narrating, reading, talking, and decreasing screen time. Increased parent-child interaction may be protective against developmental delay in infants and young children (Tamis-LeMonda, Bornstein, \& Baumwell, 2001; McDonald, Kehler, Bayarmpour, Fraser-Lee, \& Tough, 2016). By increasing parent-child interaction, upWORDS also helps families establish stronger bonds and support their children's social, emotional, and language skills, thereby potentially mitigating effects of childhood toxic stress (Garner \& Shonkoff, 2012). Decreasing screen time at an earlier age is particularly desirable, as high screen time in early childhood is associated with higher BMI and poor 
academic and psychosocial outcomes (Duch, Fisher, Ensari, \& Harrington, 2013; Pagani, Fitzpatrick, Barnett, Dubow, 2010).

Parents also felt more empowered to catalyze their children's development. As many parents better understood their role as their children's first teachers, they even began to engage their children in learning activities earlier than they would have without the program. By empowering parents, upWORDS may help increase parental self-efficacy. Parental selfefficacy is the parent's sense that he or she can fulfill the parent role successfully (Jones \& Prinz, 2005). Higher parental self-efficacy has been associated with higher parent satisfaction and better child behavior, child socio-emotional functioning, and child achievement in school (Jones \& Prinz, 2005).

With this sense of empowerment, increased parent self-efficacy, and increased knowledge of normal development, the majority of parent became more selective with child care, daycare, babysitting, and school. Because of the program, they opted for other caregivers who would also enrich their child's language environment in their absence. This gives their children the opportunity to solidify newly-learned skills, to have more continuous engagement, and to build relationships with safe, interactive, non-parenting adults. Choosing child care and school that is more interactive may also improve school readiness (Fontaine, Torre, Grawfwallner, 2006). As parents taught non-participating caregivers (such as grandparents, aunts, and friends) principles from the program, upWORDS was also able to influence community members beyond session walls. UpWORDS has the potential to positively influence community views regarding child development, adult-child interactions, and child care. 
Parents overall held positive views of their children's development after the program. Moreover, most were pleased with the positive changes noted in their child, as they perceived their children to be more interested in reading, and to have increased expressive and receptive language skills after the program. While it is difficult to delineate upWORDSassociated improvements from expected normal progression of language skills, parents nevertheless perceived this as a benefit of the program.

\section{Quantitative Data}

Each parent in this study submitted $5-6$ Snapshots for the participating child. Concerning Snapshot developmental age, participating children tended to have a baseline Snapshot developmental age that was behind their actual age. The second Snapshot developmental age was usually further behind their actual age than their baseline Snapshot developmental age was. Their Snapshot developmental age typically caught up to or surpassed their actual age by the end of the program (graduation). Months after completing the program, their developmental age generally lagged behind that of graduation.

Trends can also be observed in the Snapshot standard scores (SS). Most SS overall remained within 2 standard deviations of the mean. Participating children tended to have below average SS at baseline. The second Snapshot SS was usually lower than the baseline. Perhaps after starting upWORDS, parents became more vigilant of their children's language skills, leading to a more accurate second Snapshot SS than the baseline. Another trend is that children overall had increases in their SS during the program. At the end of the program (fourth Snapshot), most participants experience their peak SS. This supports evidence that parent-directed interventions to improve home language environment often yield positive 
results (Suskind et al, 2015; Mendelsohn et al., 2001; Sloat, Letourneau, Joschko, Schryer \& Colpitts, 2015) However these gains in the Snapshot SS do not tend to last beyond the program, as post-program scores (fifth and sixth Snapshots) declined. The difference between baseline and last Snapshot SS is variable from child to child, but the average SS were lower than their baseline. Similarly, a study by Suskind et al (2015) showed that a parent-directed language intervention program increased adult words counts, conversational turn counts, and child vocalizations during, but that these gains were not sustained after the intervention. The return of Snapshot SS to baseline may indicate a need for consistent reinforcement upWORDS program principles. Parents may also need to learn newer ageappropriate interaction techniques as their children mature. Consistent reinforcement and learning additional age-appropriate interaction techniques may be particularly important in a population that has yet to enter school (24 months -5 years) but still needs language enrichment.

\section{Integrating Quantitative and Qualitative Data}

There was no correlation between Snapshot scores and whether parents reported meeting their minimum minutes goal. Similarly, there was no correlation between final Snapshot score and parents' report of barriers, no barriers, sustained change, and unable to sustain change. The lack of relationship between Snapshot results and parent-reported experiences is likely a reflection of the study's small sample size. Since this study only had 9 participants, it was too small to delineate a statistically significant pattern within the Snapshot scores. 


\section{Limitations}

This study had several limitations. Perhaps one of the biggest limitations was a small sample size. With a convenience sample of 9 interviews, it is possible that qualitative data collection did not reach saturation, or the point in which no new information is being observed (Glaser \& Strauss, 1967). Perhaps additional subthemes could arise from more participants. With Snapshot information from only 9 families, statistical power could not be calculated. It is therefore difficult to assert that the trends in Snapshot developmental age and SS were true patterns. Some families submitted only 5 out of 6 Snapshots, further limiting interpretation of Snapshot data after graduation from upWORDS. Another limitation was potential selection bias. Parents who agreed to be interviewed may have had disproportionately more positive or negative experiences with the program, prompting them to give feedback. Compared to other parents, they also may have had more schedule availability to participate in a 30 minute interview. These parents also continued to submit Snapshot questionnaires on average of 11.7 months and 17.5 months after program graduation. They may be more motivated than other parents to submit Snapshots and may also be more motivated to continue program principles. Additionally, recall bias could have affected parents' answers on the Snapshot questionnaire and during interviews.

The quantitative arm of the study also did not have a control group. It thus cannot be determined if the trends in Snapshot data are unique to upWORDS participants or if these trends could also be seen in non-participants over time. Parents also completed 1 Snapshot at a time. There may be variability in Snapshot results that could improve by completing multiple Snapshots in a specific time period (such as calculating the mean score of 3 
Snapshots in 1 week). Furthermore, Snapshots may not be a comprehensive quantitative measure of the benefits gained from the program. Even though the study analyzed scores as far out as 17.5 months after graduation, it is still a relatively-short term measurement in the setting of child development. Some events in early childhood often have effects observable only years or even decades after. Snapshots are based on the parents' perception of their children's expressive and receptive language skills. It does not measure other potential benefits, such improvements in socio-emotional well-being and school readiness.

\section{Recommendations}

Despite its limitations, this study still gives way to several recommendations. From a programmatic standpoint, speech language pathologists should be involved in LENA Start programs when available. UpWORDS families benefited from interacting with speech language pathologists, who detected language delays and directed families to appropriate interventions. UpWORDS and other LENA Start programs should also consider providing a follow up program for previous graduates. Based on this study, the follow up program should reinforce learned behaviors, help families troubleshoot barriers to adopting behaviors, and teach normal child development and interaction techniques for older children. Such a follow up program may help sustain Snapshot SS gains and catch developmental delays manifesting beyond the original program period. In addition, upWORDS and other LENA Start programs should understand that Snapshot results may not be a sufficient measure of all the program benefits. When evaluating the program, leaders should also consider the parents' perceived 
benefits, the potential effects on the community, and potential improvements in socioemotional well-being and school readiness.

This study also highlights important points for pediatric primary care providers. For example, although the majority of children did not have developmental delays, several parents were worried about aspects of their children's speech that were actually within the range of normal. Some held these concerns even after discussing them with their children's doctors. Pediatric primary care providers should remember these parents need reassurance and that perhaps previous reassurance was misunderstood. Pediatric primary care providers should also help parents understand what behaviors and activities are appropriate according to their children's age and level of development, as recommended by the American Academy of Pediatrics (Hagan, Duncan 2017). Furthermore, pediatric primary care providers should be aware of early child language enrichment resources in their community. Programs like upWORDS can reinforce information about child development and parent-child interaction provided in pediatric clinic visits. They also provide more time to absorb and incorporate the information, compared to pediatric office visits that are typically 10-15 minutes long. Pediatric primary care providers should also be aware of online resources for parents that promote parent-child interaction and an enriched home language environment.

\section{Future Studies}

This study points to future areas of investigation. This study can be considered a pilot and should be repeated with a larger sample size. With a larger study, investigators could look for statistically significant trends in Snapshot results. They could also determine if there 
is a true relationship between Snapshot results and parent-reported experiences postgraduation (including reading minutes and challenges to applying information and sustaining behaviors). Results of Snapshots up to age 36 months should also be analyzed to look at longer-term trends, since the Snapshot Questionnaire is validated up to 36 months. Families could also be followed until their children enter school, in order to study the program's effects on school readiness. Long term socio-emotional benefits of the program should also be studied. In addition, upWORDS participants may benefit differently than other LENA Start programs because upWORDS has heavy involvement of speech language pathologists and additional parenting support topics incorporated into its curriculum. Therefore outcomes of upWORDS families, including Snapshot results, school readiness, and parent's perceptions of benefits, should be compared with those of other LENA Start programs.

Another study could focus on challenges to applying information and sustaining new behaviors from the program. Investigating why some families experienced fewer barriers and sustained changes could lead to program improvements that help families at risk of not sustaining changes. It may be helpful to ask all parents at the start of upWORDS if they foresee issues with sustaining behavior changes. This could identify at risk families and allow session facilitators to assist them with troubleshooting. Analyzing the demographic information of more families would also better characterize the population that upWORDS serves. Given the association of low SES with lower academic achievement (Hair, Hanson, Wolfe, \& Pollak, 2015; Duncan, Morris, \& Rodrigues, 2011; Hart \& Risley, 2003), increased cognitive and expressive speech delays (Hillemeier, Farkas, Morgan, Martin, Maczuga, 2009; Hammer et al., 2017), and decreased access to developmental services, (Porterfield \& 
McBride, 2007), it is important to determine if upWORDS is reaching low SES families. Cultural difference may also affect how families incorporate upWORDS principles into their lives. A study that included richer demographic data and parents' commentary on their cultural experiences may also give insight to perceived barriers and abilities to sustain behavior changes. Furthermore, parents may have felt increased pride and parent satisfaction as they witnessed their children advance in skills and as they experienced program rewards for meeting goals. The program's effects on parent's pride and parenting satisfaction should also be studied.

\section{CONCLUSION}

Parents who were at least 1 year beyond participation in upWORDS had various experiences and perceived multiple benefits that fall under the themes of child development and parent knowledge and behavior changes. Parents became more aware of developmental delays, gained a better understanding of normal child development, began to interact more with their children, and became more selective with their choices of daycare and babysitting. They perceived that as a result of the program, their children had increased interest in reading and improvements in their communication skills. While most parents had no concerns about their development, some described how upWORDS helped them seek services for undiagnosed language delays. Most parents reported no barriers to using information learned from the program and stated that they continued to apply principles after graduation. A minority parents, however, did experience barriers and had difficulty sustaining behavior change. Snapshot standard scores, an objective measure of child language skills based on 
parents' survey, tended to be lower at baseline, decrease slightly after parents began upWORDS, peak by graduation, and return to baseline or slightly below baseline after graduation. There was no pattern between Snapshot results and parents' reported challenges. The study its limitations, most notably a small sample size, possible selection bias, and an objective measure that may not fully quantify the benefits of the program. Nevertheless, this study can still provide recommendations for upWORDS and other LENA Start programs. These programs should involve speech language pathologists when available, consider providing graduates with a follow up program, and understand that Snapshot results may not be a sufficient measure of all the program's benefits. For pediatric primary care providers, this study reminds them that parents need clear reassurance on their child's development when applicable. Pediatric primary care providers should also help parents understand what is developmentally appropriate for their children and should be aware of early child language enrichment resources, both in their community and online. Opportunities for future work are many. They include studies with larger sample size, longer post-graduation times, and focuses on school readiness and challenges after graduation. 
Figure 1: LENA device

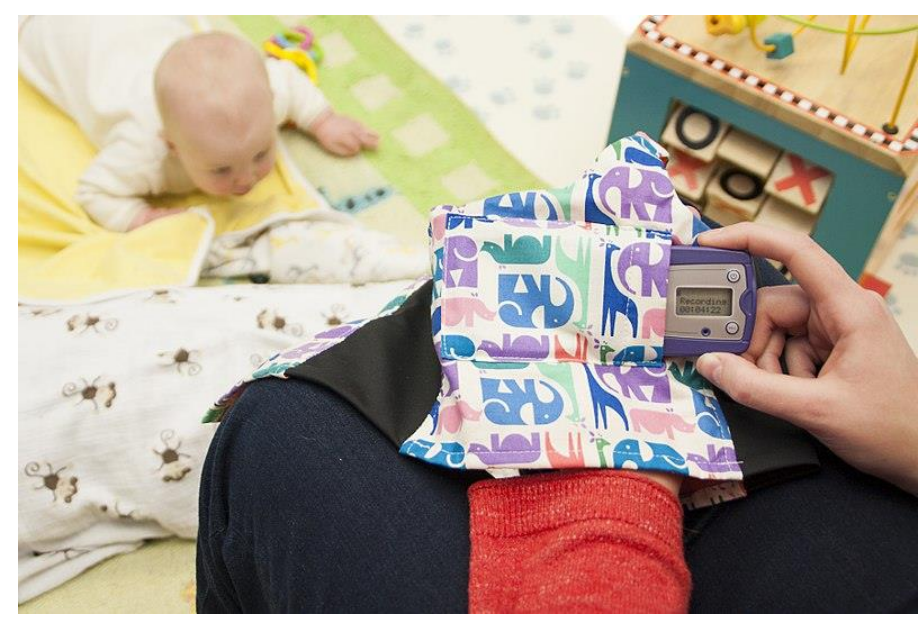

LENA device is inserted into the vest pocket. Retrieved from https://shop.lena.org/products/gender-neutral-vest-discontinued-pattern

Figure 2: LENA device vest

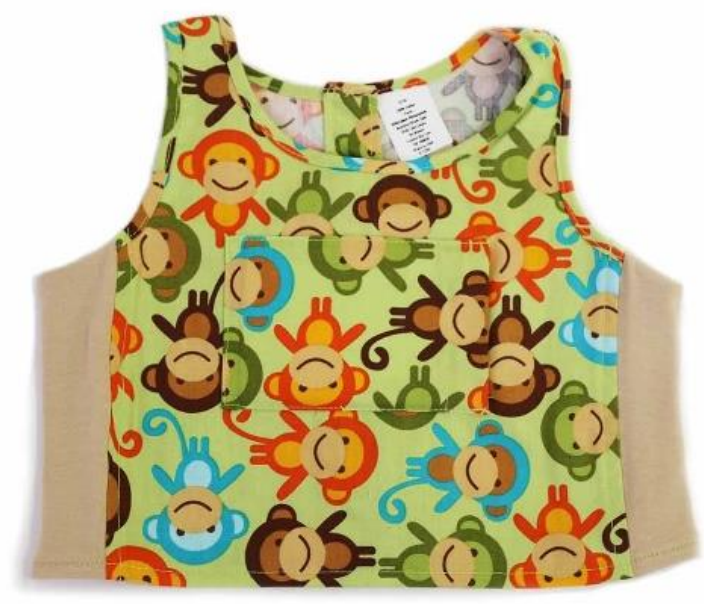

Vest is worn on recording days. Retrieved from

https://shop.lena.org/products/gender-neutral-vest-discontinued-pattern. 
Table 1: Demographics of All 9 Interviewed Families

\begin{tabular}{lrr}
\hline Child's Gender & n & \% \\
Male Child & 5 & $55.6 \%$ \\
Female Child & 4 & $44.4 \%$ \\
Language of Class & $\mathbf{n}$ & \% \\
English & 5 & $55.56 \%$ \\
Spanish & 4 & $44.44 \%$ \\
Total snapshots completed & $\mathbf{n}$ & \% \\
6 snapshots & 7 & $77.8 \%$ \\
5 snapshots & 2 & $22.2 \%$ \\
Child Age at Specific Snapshot (months) & mean & median \\
baseline snapshot & 6.6 & 6 \\
1st post-program snapshot & 22.4 & 23 \\
2nd post-program snapshot & 29 & 29 \\
Time Elapsed Since Last Class Day & days & months \\
mean time to 1st post-program & 355.9 & 11.7 \\
mean time to 2nd post-program & 531.1 & 17.5 \\
\hline
\end{tabular}

Table 2: Child Demographics from Online Survey, based on 5 total respondents

\begin{tabular}{lrr}
\hline Ethnicity & $\mathbf{n}$ & $\mathbf{\%}$ \\
Hispanic/Latino & 3 & $60 \%$ \\
Non-Hispanic & 2 & $40 \%$ \\
Race & & \\
White & 5 & $100 \%$ \\
Health Insurance Coverage & & \\
No coverage & 1 & $20 \%$ \\
Medicaid/CHIP/ Texas Health Steps & 2 & $40 \%$ \\
Private & 2 & $40 \%$ \\
NICU Admission After Delivery & & \\
Yes & 2 & $40 \%$ \\
No & 3 & $60 \%$ \\
Newborn Hearing Screen & & \\
Passed & 5 & $100 \%$ \\
Diagnosed With a Special Need* & \\
No & 5 & $100 \%$ \\
\hline *Parents were asked if a medical professional diagnosed the child with a special need, such as a developmental delay, \\
learning disability, speech delay, or emotional disorder
\end{tabular}


Table 3: Parent Demographics from Online Survey, based on 5 total respondents

\begin{tabular}{|c|c|c|}
\hline Parent Age & \multicolumn{2}{|c|}{ years } \\
\hline Mean Age & \multicolumn{2}{|c|}{32.4} \\
\hline Median Age & \multicolumn{2}{|c|}{33} \\
\hline Relationship to Child & $\mathbf{n}$ & $\%$ \\
\hline Mother & & $100 \%$ \\
\hline \multicolumn{3}{|l|}{ Ethnicity } \\
\hline Hispanic/Latino & & $60 \%$ \\
\hline Non-Hispanic & 2 & $40 \%$ \\
\hline \multicolumn{3}{|l|}{ Race } \\
\hline White & 5 & $100 \%$ \\
\hline \multicolumn{3}{|l|}{ Marital Status } \\
\hline Not married & 1 & $20 \%$ \\
\hline Married & 4 & $80 \%$ \\
\hline \multicolumn{3}{|l|}{ Country of Birth } \\
\hline USA & 2 & $40 \%$ \\
\hline Outside of the USA & 3 & $60 \%$ \\
\hline \multicolumn{3}{|l|}{ Education Level } \\
\hline Some college & 1 & $20 \%$ \\
\hline Graduated college & 3 & $60 \%$ \\
\hline Post-graduate education & 1 & $20 \%$ \\
\hline \multicolumn{3}{|c|}{ Receives Public Assistance* } \\
\hline Yes & 1 & $20 \%$ \\
\hline No & 4 & $80 \%$ \\
\hline \multicolumn{3}{|c|}{ Annual Household Income } \\
\hline$\$ 25,001-\$ 50,000$ & 3 & $60 \%$ \\
\hline$\$ 50,001-\$ 75,000$ & 1 & $20 \%$ \\
\hline$>\$ 100,000$ & 1 & $20 \%$ \\
\hline
\end{tabular}


Figure 3: Chronological Age vs Snapshot age

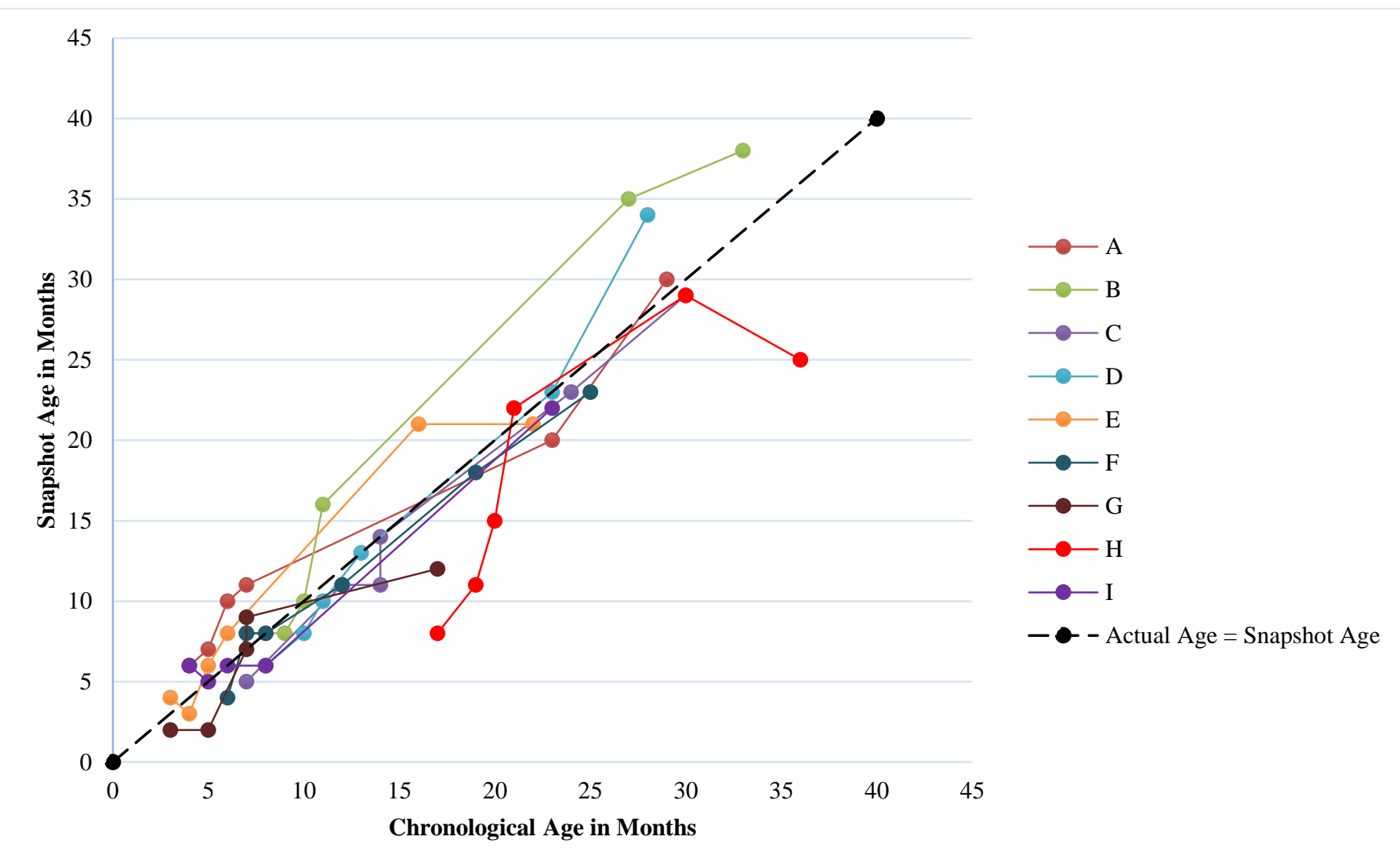


Table 4: Snapshot Standard Scores (SS) submitted by interviewed parents

\begin{tabular}{|c|c|c|c|c|c|c|c|c|c|c|c|c|}
\hline \multirow{2}{*}{$\begin{array}{r}\text { Snapshot } \\
\text { Child }\end{array}$} & \multicolumn{2}{|c|}{ Baseline } & \multicolumn{2}{|c|}{ 2nd } & \multicolumn{2}{|c|}{ 3rd } & \multicolumn{2}{|c|}{ 4th } & \multicolumn{2}{|c|}{ 5th } & \multicolumn{2}{|c|}{ 6th } \\
\hline & SS & $\Delta$ & SS & $\Delta$ & SS & $\Delta$ & SS & $\Delta$ & SS & $\Delta$ & SS & $\Delta$ \\
\hline A & 129.63 & 29.63 & 124.9 & 24.9 & 136 & 36 & 136 & 36 & 88.83 & -11.17 & 100.75 & 0.75 \\
\hline B & 118.4 & 18.4 & 104.57 & 4.57 & 107.33 & 7.33 & 132.71 & 32.71 & 118.19 & 18.19 & 114.67 & 14.67 \\
\hline $\mathrm{C}$ & 90.52 & -9.48 & 100.25 & 0.25 & 90.8 & -9.2 & 103.84 & 3.84 & 93.02 & -6.98 & 93.49 & -6.51 \\
\hline D & 90.98 & -9.02 & 99 & -1 & 101.7 & 1.7 & 105.66 & 5.66 & 96.39 & -3.61 & 113.02 & 13.02 \\
\hline E & 100.72 & 0.72 & 83.61 & -16.39 & 109.9 & 9.9 & 127.76 & 27.76 & 121.37 & 21.37 & 94.85 & -5.15 \\
\hline $\mathrm{F}$ & 89.46 & -10.54 & 118.4 & 18.4 & 110.91 & 10.91 & 100.25 & 0.25 & 95.88 & -4.12 & 89.86 & -10.14 \\
\hline G & 76.72 & -23.28 & 72.4 & -27.6 & 107.24 & 7.24 & 123.97 & 23.97 & 84.36 & -15.64 & & \\
\hline $\mathrm{H}$ & 69.91 & -30.09 & 74.11 & -25.89 & 83.93 & -16.07 & 101.19 & 1.19 & 93.49 & -6.51 & 70.73 & -29.27 \\
\hline I & 129.63 & 29.63 & 102.4 & 2.4 & 102.23 & 2.23 & 95.96 & -4.04 & 93.87 & -6.13 & & \\
\hline mean & & -0.45 & & -2.26 & & 5.56 & & 14.15 & & -1.62 & & -3.23 \\
\hline
\end{tabular}


Figure 4: Snapshot Number vs. Snapshot Standard Score

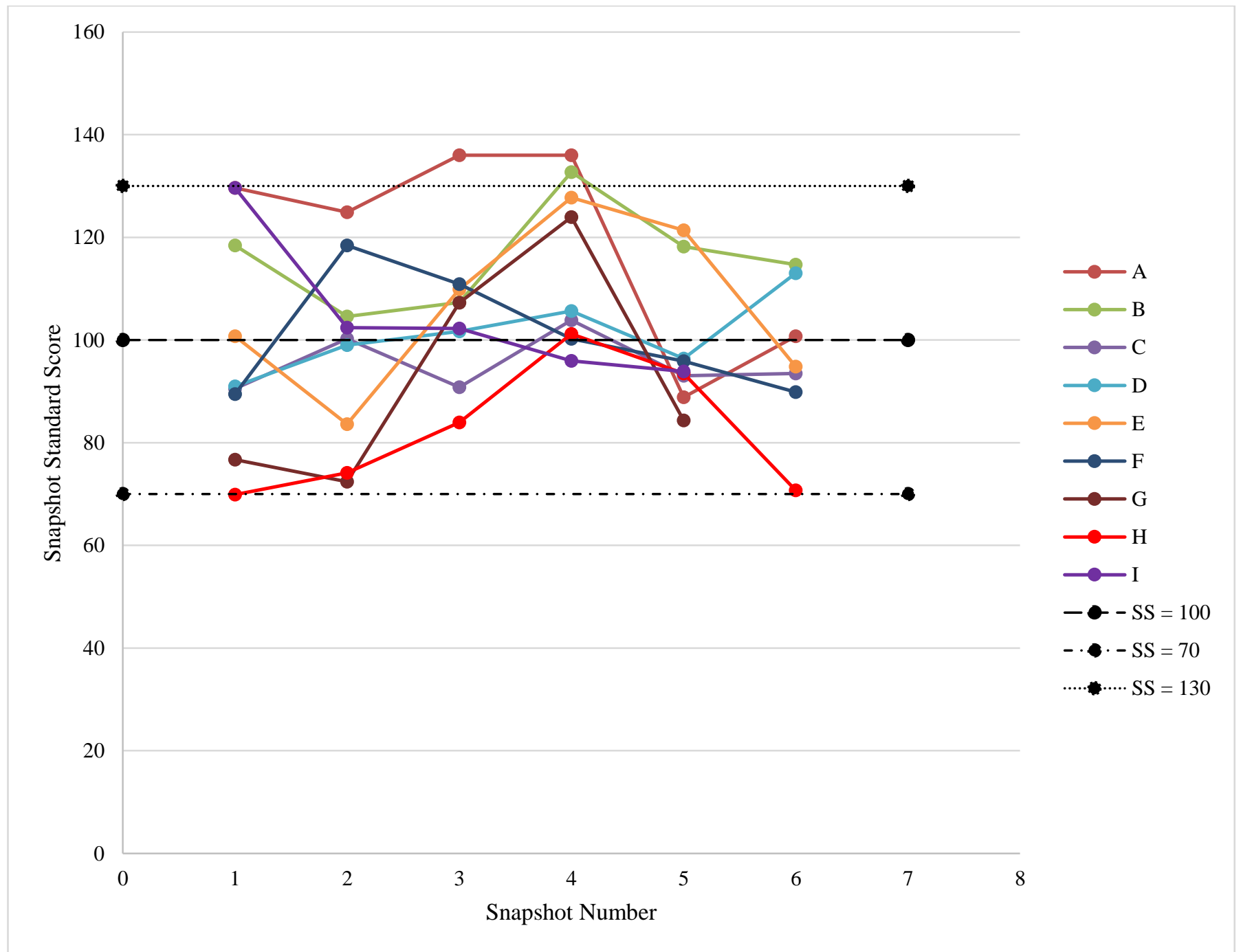




\section{APPENDICES}

\section{Appendix A: LENA Start Curriculum Outline}

Session 1: Introduction to LENA Start

Session 2: LENA Reports and the 14 Talking Tips

Session 3: Shared Reading

Session 4: Songs and Rhymes

Session 5: Talking Tips Practice and Group Report

Session 6: More About Your Baby's Brain

Session 7: Midpoint Reflections

Session 8: Math Talk - Movement

Session 9: Building Brains by Asking Questions

Session 10: Language of Food

Session 11: Math Talk - Space

Session 12: Out and About

Session 13: Graduation Day 


\section{Appendix B: Interview Guide Questions}

\section{REFLECTIONS OF THE UPWORDS PROGRAM}

Please take a moment to reflect on your experience with the upWORDS program.

1. How, if any, has your participation in the program influenced your interaction with your child?

a. Can you give an example/some examples?

b. Have you been able to sustain this after finishing the program?

Prompt (if needed) - Some of the key elements of the upWORDS program are the "14

Talking Tips" (Reading to your child, purposeful conversations, etc).

2. How, if any, has your participation in the program influenced your knowledge and expectations of your child's development?

a. Can you give an example/some examples?

3. If the upWORDS program has had no impact on your interaction with your child or your knowledge of your child's development, what knowledge or skill set were you hoping to gain from participating in the program?

4. Can you tell me about your experience in using the LENA devices (the digital recorders) to measure the number of adult words that your child was exposed to and your conversational turns with your child? If at all, how did your behaviour change on the days that you were recording? (On the recording days, did you feel that you needed to act differently than on days where you were not recording?) Did your feelings about the recorders change as you progressed through the program (was it different at the beginning, middle, or end?)

5. Since participating in the program, have you experienced any barriers or difficulties in using the information taught during the program?

a. What do you think need to overcome these barriers/difficulties?

6. What do you feel was the most beneficial part of the upWORDS program for you and your child? What was the most important thing that you learned from the program?

7. Was there anything that you didn't like about the upWORDS program? If you could change just one thing about the program, what would it be?

8. Was the program too short, too long, or just right in terms of its length? Why? How long do you think it should be? Was there enough time to cover everything that you 
wanted to cover? What things would you have liked to cover that you didn't? Was time spent on something that you thought could be omitted?

9. Since participating in the program, have you kept in contact with any of the other families that participated in the program with you? If so, can you give examples?

10. Do you think program has affected how you think about child care, day care, babysitting, or school?

a. Can you explain or give examples?

\section{QUESTIONS ABOUT YOUR CHILD}

Now we will transition to discuss your child that participated in the upWORDS program.

11. How old is your child now?

12. What do you think about your child's language development? How do you think it compares to other children that are your child's age?

a. Can you give examples?

13. Do you have any concerns about your child's development?

a. Please explain why or why not

14. Has your child seen a doctor any time after finishing the program?

a. Has a doctor been worried or concerned about your child's development? If so, please explain why

15. On average, how much time is your child read to per day? And by whom?

\section{CONCLUSION}

Thank you for sharing your expertise. Before we finish, is there anything else that you think would be helpful for us to know to improve the Texas Children's Hospital upWORDS Program? 


\section{Appendix C: Codebook}

1. Child Development

a. Child's interest in reading

b. Child's communication

i. Receptive language

ii. Expressive language

c. Were there concerns about child development?

i. Parent not concerned

ii. Doctor not concerned

iii. Parent concerned but doctor not concerned

iv. Concerns

1. Parent concerned

2. Developmental disorder diagnosed or being investigated

2. Parent Knowledge and Behavior Change

a. Awareness of developmental delay

b. Better understanding of normal child development

i. General child development

ii. Language development

iii. Empower parent to be key agents in child's development

iv. Early engagement

c. Did the program have an impact on parent's thoughts or decisions regarding child care, daycare, babysitting, or school?

i. Impact

ii. No impact

d. Parent-child interaction

i. General parent-child interaction

ii. Specific parent-child interaction techniques

1. Narrating

2. Reading

3. Talking with the child

4. Screen time

e. Challenges to applying information and sustaining behaviors

i. Barriers

ii. No barriers

iii. Sustained change

iv. Unable to sustain change

v. Caregiver reading count 


\section{Appendix D: Baylor College of Medicine IRB Letter of Approval}

January 23, 2019

KIMBERLY KAY LOPEZ

BAYLOR COLLEGE OF MEDICINE

PEDIATRICS: PUBLIC HEALTH

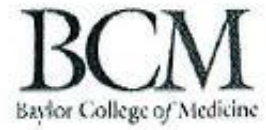

Baylor College of Medicine Office of Research

One Baylor Plaza, 600D

Houston, Texas 77030

Phone: (713) 798-6970

Fax: (713) 798.6990

Email: irb@bem.tunc.edu

H-40882 - PARENTING EDUCATION PROGRAM EVALUATION

APPROVAL VALID FROM 1/23/2019 TO 1/22/2020

Dear Dr. LOPEZ

The Institutional Review Board for Human Subject Research for Baylor College of Medicine and Affiliated Hospitals (BCM IRB) is pleased to inform you that the research protocol and consent form(s) named above were reviewed and approved by Expedited procedures on 1/23/2019 by Board 1 .

The study may not continue after the approval period without additional IRB review and approval for continuation. You will receive an email renewal reminder notice prior to study expiration; however, it is your responsibility to assure that this study is not conducted beyond the expiration date.

Please be aware that only IRB-approved informed consent forms may be used when written informed consent is required.

Any changes in study or informed consent procedure must receive review and approval prior to implementation unless the change is necessary for the safety of subjects. In addition, you must inform the IRB of adverse events encountered during the study or of any new and significant information that may impact a research participants' safety or willingness to continue in your study.

The BCM IRB is organized, operates, and is registered with the United States Office for Human Research Protections according to the regulations codified in the United States Code of Federal Regulations at 45 CFR 46 and 21 CFR 56. The BCM IRB operates under the BCM Federal Wide Assurance No. 00000286, as well as those of hospitals and institutions affiliated with the College.

Sincerely yours,

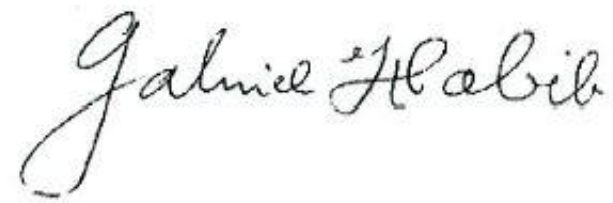

GABRIEL HABIB, M.D.

Institutional Review Board for Baylor College of Medicine and Affiliated Hospitals

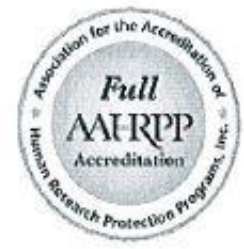




\section{REFERENCES}

(2014, April 8). LENA Vest with LENA Device [digital image]. Retrieved from https://commons.wikimedia.org/wiki/File:LENA_Vest_with_LENA_Device.jpg.

Butchart, A., Harvey, A.P., Mian, M., Fürniss, T. (2006). Preventing Child Maltreatment: A guide to taking action and generating evidence. T. Kahane (Ed.). Geneva, Switzerland: World Health Organization Press.

Cohen, A.K., \& Syme, S.L. (2013). Education: a Missed Opportunity for Public Health Intervention. American Journal of Public Health, 103(6), 997-1001. http://ajph.aphapublications.org/doi/10.2105/AJPH.2012.300993.

Diner, M.L., Hobson-Rohrer, W., \& Byington, C.L. (2012). Kindergarten Readiness and Performance of Latino Children Participating in Reach Out and Read. Journal of Community Medicine and Health Education, 2(3). doi: 10.4172/2161-0711.1000133.

Duch, H., Fisher, E.M., Ensari, I., Harrington, A. (2013). Screen time use in children under 3 years old: a systematic review of correlates. International Journal of Behavioral Nutrition and Physical Activity, 10(102), 1-10. doi: 10.1186/1479-5868-10-102.

Duncan, G.J., Morris, P.A., \& Rodrigues, C. (2011). Does Money Really Matter? Estimating Impacts of Family Income on Young Children's Achievement with Data from Random-Assignment Experiments. Developmental Psychology, 47(5), 1263-1279. http://dx.doi.org/10.1037/a0023875. 
Fontaine, N. S., Torre, D. L., \& Grafwallner, R. (2006). Effects of quality early care on school readiness skills of children at risk. Early Child Development and Care, 176(1), 99-109.

Garner, A.S., Shonkoff, J.P., \& Committee on Psychosocial Aspects of Child and Family Health, Committee on Early Childhood, Adoption, and Dependent Care, Secition on Developmental and Behavioral Pediatrics. (2012). Early childhood adversity, toxic stress, and the role of the pediatrician: translating developmental stress into lifelong health. Pediatrics, 129(1), e224-231. doi: 10.1542/peds.2011-2662.

Gilkerson, J., Richards, J., Greenwod, C., \& Montgomery, J. (2016). Language assessment in a snap: Monitoring progress up to 36 months. Child Language Teaching and Therapy, 33(2), 99-115. https://doi.org/10.1177/0265659016660599.

Glaser, B.G., \& Strauss, A.L. (1967). The Discovery of Grounded Theory: Strategies for Qualitative Research. New Brunswick, NJ: Aldine Transaction.

Golinkoff, R.M., Hoff, E., Rowe, M.L., Tamis-LeMonda, C.S., \& Hirsh-Pasek, K. (2018). Language Matters: Denying the Existence of the 30-Million-Word Gap Has Serious Consequences. Child Development. https://doi.org/10.1111/cdev.13128

Hagan, J.F., Shaw, J.S., Duncan, P.M. (Eds.). (2017). Bright Futures: Guidelines for Health Supervision of Infants, Children, and Adolescents ( $4^{\text {th }}$ ed.). Elk Grove Village, IL: American Academy of Pediatrics. 
Hahn, R., \& Truman, B. (2015). Education Improves Public Health and Promotes Health Equity. International Journal of Health Services, 45(4), 657-678. doi: $10.1177 / 0020731415585986$

Hair, N.L, Hanson, J.L., Wolfe, B.L., \& Pollak, S.D. (2015). Association of Child Poverty, Brain Development, and Academic Achievement. JAMA Pediatrics, 169(9), 822-829. doi:10.1001/jamapediatrics.2015.1475

Hammer, C.S., Morgan, P., Farkas, G., Hillemeier, M., Bitetti, D., \& Maczuga, S. (2017). Late Talkers: A Population-Based Study of Risk Factors and School Readiness Consequences. Journal of Speech, Language, and Hearing Research, 60, 607-626. https://doi.org/10.1044/2016_JSLHR-L-15-0417.

Hart, B., \& Risley, T. (2003). The Early Catastrophe: The 30 Million Word Gap by Age 3. American Educator, Spring. 4-9.

Hillemeier, M.M, Farkas, G., Morgan, P.L., Martin, M.A., \& Maczuga, S.A. (2009). Disparities in the Prevalence of Cognitive Delay: How Early Do They Appear? Paediatric Perinatal Epidemiology, 23(3), 186-198. doi:10.1111/j.13653016.2008.01006.x. 
Huang, K., Caughy, M.O., Genevro, J.L., Miller, T.L. (2005). Maternal knowledge of child development and quality of parenting among White, African-American and Hispanic mothers. Journal of Applied Developmental Psychology, 26(2), 149-170. https://doi.org/10.1016/j.appdev.2004.12.001.

Jones, T.L., Prinz, R.J. (2005). Potential roles of parental self-efficacy in parent and child adjustment: A review. Clinical Psychology Review, 25(3), 341-363. https://doi.org/10.1016/j.cpr.2004.12.004.

Koball, H, \& Jiang, Y. (2018). Basic Facts about Low-Income Children: Children Under 9 Years, 2016. New York: National Center for Children in Poverty, Columbia University Mailman School of Public Health. Retrieved from http://www.nccp.org/publications/pdf/text_1195.pdf.

LENA (Photographer). Gender Neutral Vest-Discontinued Pattern [digital image]. Retrieved from https://shop.lena.org/products/gender-neutral-vest-discontinuedpattern.

McDonald, S., Kehler, H., Bayarmpour, H., Fraser-Lee, N., Tough, S. (2016). Risk and protective factors in early child development: Results from the All Our Babies (AOB) pregnancy cohort. Research in Developmental Disabilities, 58, 20-30. https://doi.org/10.1016/j.ridd.2016.08.010. 
McQuiston, S., Kloczko, N. (2011). Speech and Language Development: Monitoring Process and Problems. Pediatrics in Review, 32(6), 230-239.

Mendelsohn, AL., Mogilner, L.N., Dreyer, B.P., Forman, J.A, Weinstein, S.C, Broderick M., Cheng, K.J., Magloire, T. Moore, T., \& Napier, C. (2001). The Impact of a ClinicBased Literacy Intervention on Language Development in Inner-City Preschool Children. Pediatrics, 107(1), 130-134.

National Center for Children in Poverty. (2018). Texas Demographics of Poor Children. National Center for Children in Poverty, Columbia University Mailman School of Public Health. Retrieved from http://www.nccp.org/profiles/TX_profile_7.html.

NICHD Early Child Care Research Network. (2005). Pathways to Reading: The Role of Oral language in the Transition to Reading. Developmental Psychology, 41(2). 428-442. http://dx.doi.org/10.1037/0012-1649.41.2.428.

Pagani, L.S., Fitzpatrick, C., Barnett, T.A., Dubow, E. (2010). Prospective associations between early childhood television exposure and academic, psychosocial, and physical well-being by middle childhood. Archives of Pediatric and Adolescent Medicine, 165(5), 425-431. doi:10.1001/archpediatrics.2010.50 
Porterfield, S.L., \& McBride, T.D. (2007). The Effect of Poverty and Caregiver Education on Perceived Need and Access to Health Services Among Children with Special Health Care Needs. American Journal of Public Health, 97(2), 323-329. doi: 10.2105/AJPH.2004.055921.

Sloat, E.A., Letourneau, N.L., Joschko, J.R., Schryer, E.A., Colpitts, J.E. (2015). ParentMediated Reading Interventions With Children Up To Four Years Old: A Systematic Review. Issues in Comprehensive Pediatric Nursing, 38(1), 39-56. https://doi.org/10.3109/01460862.2014.983279

Sperry, D.E., Sperry, L.L., \& Miller, P.J. (2018). Reexamining the Verbal Environment of Children from Different Socioeconomic Backgrounds. Child Development. doi: 10.1111/cdev.13072.

Suskind, D.L., Leffel, K.R., Graf, E., Hernandez, M.W., Gunderson, E.A., Sapolich, S.G., Suskind, E. Leininger, L., Golind-Meadow, S., \& Levine, S.C. (2015). A parentdirected language intervention for children of low socioeconomic status: a randomized controlled pilot study. Journal of Child Language, 43(2), 366-406. https://doi.org/10.1017/S0305000915000033.

Tamis-LeMonda, C.S., Bornstein, M.H., \& Baumwell, L. (2001). Maternal Responsiveness and Children's Achievement of Language Milestones. Child Development, 72(3), 746-767. https://doi.org/10.1111/1467-8624.00313. 
Weisleder, A. \& Fernald, A. (2013). Talking to Children Matters: Early Language Experience Strengthens Processing and Builds Vocabulary. Psychology Science, 24(1), 2143-2152. https://doi.org/10.1177/0956797613488145. 